\title{
Capaian Standar Pengelolaan Pendidikan pada SD,
SMP dan SMA Islam di Kota Bandung
}

Dini Irawati ${ }^{1}$, Maman $^{2}$, Agus Sumpena ${ }^{3}$, Muhibbin Syah ${ }^{4}$, Mohamad Erihadiana ${ }^{5}$

1,2,3,4,5Universitas Islam Negeri Sunan Gunung Djati Bandung, Indonesia

E-mail:diniirawati321@gmail.com, maman@unpas.ac.id, agussumpena17@gmail.com, muhibbinsyah@yahoo.com, erihadiana@uinsgd.ac.id

\begin{tabular}{l}
\hline Article Info \\
\hline Article Histo \\
Received: 2021 \\
Revised: 2021 \\
Published: 202 \\
\\
Keywords: \\
Standard; \\
Management; \\
Education; \\
Islam.
\end{tabular}

\begin{abstract}
This study aims to describe the achievement of quality management standards at primary and secondary Islamic schools in the city of Bandung based on the results of the 2020 quality report cards. The results of the analysis show the achievement of quality management standards which include 4 components, namely the school carries out management planning, the management program is carried out according to the provisions, the Principal schools perform well in carrying out leadership tasks, and schools manage management information systems, in the last four years the trend has shown an increase of 39\%. The achievement of Islamic school management standards in Bandung City in 2020 is included in the category Towards SNP 4. Of the 16 indicators in the management standard, there are 6 indicators with the lowest scores that need attention to be prioritized in an effort to meet national education standards, namely 1) student service programs, 2) entrepreneurial competence of school principals, 3) management of management information systems, 4) curriculum management, 5) utilization of educators and education personnel and 6) partnership development. Through root cause-based analysis, in order to improve the achievement of quality standards in the management of education units, education providers need to implement education quality assurance systems both internally and externally, capacity building programs for principals and development of partnership programs with relevant agencies.
\end{abstract}

\begin{abstract}
Abstrak
Penelitian ini bertujuan untuk menggambarkan capaian mutu standar pengelolaan pada sekolah islam jenjang dasar dan menengah di kota Bandung berdasarkan hasil rapor mutu tahun 2020. Hasil analisis menunjukkan capaian mutu standar pengelolaan yang mencakup 4 komponen yaitu Sekolah melakukan perencanaan pengelolaan, Program pengelolaan dilaksanakan sesuai ketentuan, Kepala sekolah berkinerja baik dalam melaksanakan tugas kepemimpinan, dan Sekolah mengelola sistem informasi manajemen, pada empat tahun terakhir kecenderungannya menunjukkan peningkatan sebesar 39 \%. Capaian standar pengelolaan Sekolah Islam di Kota Bandung pada tahun 2020 termasuk pada kategori Menuju SNP 4. Dari 16 indikator pada standar pengelolaan terdapat 6 indikator dengan nilai terendah yang perlu menjadi perhatian untuk diprioritaskan dalam upaya memenuhi standar nasional pendidikan yaitu 1) program layanan kesiswaan, 2) kompetensi kewirausahaan kepala sekolah, 3) pengelolaan sistem informasi manajemen, 4) pengelolaan kurikulum, 5) pendayagunaan pendidik dan tenaga kependidikan dan 6) pengembangan kemitraan. Melalui analisis berbasis akar masalah maka untuk meningkatkan capaian mutu standar pengelolaan satuan Pendidikan, penyelenggara Pendidikan perlu menerapkan sistem penjaminan mutu Pendidikan baik secara internal maupun eksternal, program peningkatan kapasitas kepala sekolah dan pengembangan program kemitraan dengan instansi yang relevan.
\end{abstract}

\section{PENDAHULUAN}

Penjaminan mutu merupakan sebuah kewajiban dalam rangka membangun mutu sebuah lembaga pendidikan. Menurut (Arifudin, 2019) bahwa proses penjaminan mutu pendidikan merupakan tanggung jawab semua pihak yang terkait (stakeholders), mulai dari pemerintah pusat, pemerintah daerah (provinsi/kabupaten/kota), hingga satuan pendidikan. Ketiga pihak tersebut perlu memiliki komitmen yang kuat untuk samasama berkolaborasi dan bersinergi dalam proses penjaminan mutu pendidikan, karena jika ada salah satu pihak yang kurang optimal atau kurang memiliki komitmen dalam melakukan penjaminan mutu pendidikan, maka tujuan untuk mencapai 8 SNP sebagaimana yang diharapkan 
sulit untuk bisa terwujud. 8 SNP tersebut meliputi: (1) Standar Kelulusan, (2) Standar Isi, (3) Standar Proses, (4) Standar Pendidik dan Tenaga Kependidikan, (5) Standar Sarana dan Prasarana, (6) Standar Pengelolaan, (7) Standar Pembiayaan, dan (8) Standar Penilaian Pendidikan.

Pengelolaan penyelenggaraan pendidikan diartikan sebagai suatu rangkaian pekerjaan atau usaha yang dilakukan oleh sekelompok orang untuk melakukan serangkaian kerja dalam mencapai tujan tertentu (Na'im, 2021). Definisi pengelolaan oleh para ahli terdapat perbedaan-perbedaan. Hal ini disebabkan karena para ahli meninjau pengertian dari sudut pandang yang berbeda-beda. Ada yang meninjau pengelolaan dari segi fungsi, benda, kelembagaan dan yang meninjau pengelolaan sebagai suatu kesatuan. Namun jika dipelajari pada prinsipnya definisi-definisi tersebut mengandung pengertian dan tujuan yang sama.

Menurut (Afifudin, 2008) bahwa pengelolaan pendidikan merupakan serangkaian kegiatan merencanakan, mengorganisasikan, memotivasi, mengendalikan, dan mengembangkan segala upaya didalam mengatur dan mendayagunakan sumber daya manusia, sarana dan prasarana untuk mencapai tujuan pendidikan. Minimal tiga dimensi penting didalam konsep pengelolaan. Dimensi pertama, dalam pengelolaan terjadi kegiatan yang dilakukan oleh seseorang pengelola (Pemimpin, kepala, komandan dsb). Dimensi ini menunjukkan betapa pentingnya kemampuan dan keteramplan khusus yang perlu dimiliki oleh pengelola untuk melakukan hubungan kemanusiaan dan untuk mempengaruhi orang lain baik melalui hubungan perorangan maupun melalui hubungan kelompok. Dimensi kedua, menunjukkan bahwa kegiatan yang dilakukan bersama dan melalui orang lain itu mempunyai tujuan yang hendak dicapai. Sedangkan dimensi ketiga, pengelolaan itu dilakukan dalam organisasi, sehingga tujuan organisasi dicapai melalui kegiatan yang dilakukan bersam orang lain baik perorangan maupun kelompok.

Menurut Wardoyo dalam (Irwansyah, 2021), pengelolaan adalah suatu rangkai kegiatan yang berintikan perencanaan, pengorganisasian penggerakan dan pengawasan dalam mencapai tujuan yang telah ditetapkan sebelumnya. Menurut (Raharjo, 2018) bahwa pengelolaan adalah suatu istilah yang berasal dari kata "kelola" mengandung arti serangkaian usaha yang bertujuan untuk menggali dan memanfaatkan segala potensi yang dimiliki secara efektif dan efisien guna mencapai tujuan tertentu yang telah direncanakan sebelumnya.

Dari uraian diatas dapatlah disimpulkan bahwa yang dimaksud dengan pengelolaan adalah suatu rangkaian kegiatan yang berintikan perencanaan, pengorganisasian, penggerakan dan pengawasan yang bertujuan menggali dan memanfaatkan sumber daya alam yang dimiliki secara efektif untuk mencapai tujuan organisasi yang telah ditentukan. Pengelolaan pendidikan berasal dari kata manajemen, sedangkan istilah manajemen sama artinya dengan administrasi. Dapat diartikan pengelolaan pendidikan sebagai upaya untuk menerapkan kaidah-kaidah adiministrasi dalam bidang pendidikan. Standar pengelolaan adalah standar nasional pendidikan yang berkaitan dengan perencanaan, pelaksanaan, dan pengawasan kegiatan pendidikan pada tingkat satuan pendidikan, kabupaten/kota, provinsi, atau nasional agar tercapai efisiensi dan efektivitas penyelenggaraan pendidikan. Pengelolaan satuan pendidikan menjadi tanggung jawab kepala satuan pendidikan.

Secara yuridis standar pengelolaan pendidikan, telah ditetapkan oleh pemerintah melalui Peraturan Pemerintah Nomor 57 Tahun 2021, yang merupakan perubahan ketiga dari Peraturan Pemerintah nomor 19 Tahun 2005 tentang Standar Nasional Pendidikan. Disebutkan pada pasal 27 ayat 1 bahwa "Standar pengelolaan merupakan kriteria minimal mengenai perencanaan, pelaksanaan, dan pengawasan kegiatan pendidikan yang dilaksanakan oleh Satuan Pendidikan agar penyelenggaraan Pendidikan efisien dan efektif.

Selanjutnya standar pengelolaan diatur melalui Peraturan Menteri Pendidikan Nasional nomor 19 Tahun 2007 tentang Standar Pengelolaan Pendidikan Oleh Satuan Pendidikan Dasar Dan Menengah. Pada peraturan ini telah diatur bahwa standar pengelolaan Pendidikan pada satuan Pendidikan dasar dan menengah secara umum terdiri dari 4 komponen yaitu 1) perencanaan program, 2) pelaksanaan rencana kerja, 3) pengawasan dan evaluasi dan 4) sistem informasi manajemen. Komponen yang telah diatur pada peraturan ini yang akan menjadi acuan dalam mengukur capaian mutu standar pengelolaan yang dikembangkan menjadi instrumen pemetaan mutu Pendidikan dan menghasilkan rapor mutu satuan Pendidikan secara berkala setiap tahun.

Untuk mengukur keterlaksanaan standar nasional pendidikan, sejak pada tahun 2009 pemerintah menerbitkan (permendiknas no 63 
tahun 2009 7) yang mengatur tentang sistem penjaminan mutu Pendidikan, maka mulai dirancang alat untuk mengukur capaian standar nasional pendidikan baik oleh pihak internal maupun eksternal. Alat ukur atau instrument ini diisi secara rutin oleh setiap satuan pendidikan sebagai alat evaluasi diri dan dijadikan acuan dalam Menyusun program dan kegiatan sekolah dalam upaya meningkatkan mutu SNP.

Secara konsisten mulai tahun 2013 hingga sekarang setiap sekolah diwajibkan untuk mengisi instrument ini, yang kemudian selain dijadikan bahan penyusunan rencana kerja sekolah, namun juga dijadikan dalam penentu kebijakan peningkatan mutu di level makro yaitu untuk pemerintah pusat dalam hal ini adalah kementerian Pendidikan dan kebudayaan. Mulai tahun 2016 sejak ditetapkannya peraturan Menteri Pendidikan dan Kebudayaan no 28 Tahun 2016. Tentang system penjaminan mutu Pendidikan dasar dan menengah maka secara masiv semua sekolah mulai menerapkan system penjaminan mutu internal yang bertujuan untuk mempercepat terpenuhinya standar nasional Pendidikan .

Acuan utama dalam menerapkan sistem penjaminan mutu ini 8 standar nasional Pendidikan yang dilihat dari hasiladalah rapor mutu tahunan pada satuan pendidikan,. Rapor Mutu sekolah adalah rapor kemajuan sekolah yang berbasis kepada 8 Standar Nasional Pendidikan dengan indikator dan sub indikator yang berisi nilai dengan skala 1-7. Rapor mutu sekolah menggambarkan kondisi sekolah dalam upaya pemenuhan Standar Nasinal Pendidikan. Rapor mutu menjadi salah satu data yang digunakan dalam merumuskan kebijakan peningkatan mutu baik di level satuan Pendidikan maupun di level pemerintah daerah dan pemerintah pusat.

Pemerintah pusat dan pemerintah daerah membuat sebuah sistem (regulasi, program, dan kebijakan) untuk memayungi proses penjaminan mutu pendidikan, sedangkan menurut (Arifudin, 2020) bahwa satuan pendidikan melaksanakan Sistem Penjaminan Mutu Internal (SPMI) sebagai sebuah kebutuhan bahkan sebagai budaya yang perlu ditumbuhkan dalam rangka meningkatkan mutu secara bertahap dan berkelanjutan. Adapun Sistem Penjaminan Mutu Eksternal (SPME) dilakukan melalui akreditasi oleh Badan Akreditasi Nasional Sekolah/Madrasah (BAN-S/M).

Data merupakan hal yang sangat penting dan sangat diperlukan sebagai dasar pengambilan sebuah kebijakan. Dalam konteks mutu pendidikan, Kemdikbud telah menyiapkan sistem bagi satuan pendidikan untuk mengirimkan data-data terkait dengan pencapaian 8 SNP melalui website http://pmp.dikdasmen.kemdikbud.go.id, Setiap satuan pendidikan diharapkan dapat mengirimkan data capaian 8 SNP secara lengkap, objektif, akurat, dan akuntabel, karena data-data tersebut nantinya akan menjadi rapor mutu satuan pendidikan dan akan menjadi dasar penyusunan rekomendasi peningkatan mutu baik bagi satuan pendidikan maupun bagi pemerintah daerah (Hasbi, 2021).

Layanan pendidikan di satuan pendidikan jika dilihat dari pengelompokannya terbagi kepada dua bagian besar yaitu bidang akademik dan bidang manajerial. Untuk memastikan kedua bidang ini dapat berfungsi, maka standar pengelolaan merupakan salah satu dari standar nasional pendidikan yang mengukur ketercapaian atau keterlaksanaan kegiatan manajerial di sekolah. Sehingga standar pengelolaan ini merupakan salah satu standar nasional pendidikan yang cukup berpengaruh terhadap ketercapaian standar kompetensi lulusan (Arifudin, 2021).

\section{METODE PENELITIAN}

Penelitian ini berusaha untuk menganalisis dan mendeskripsikan Capaian Standar Pengelolaan Pendidikan Pada SD, SMP Dan SMA Islam Di Kota Bandung. Jenis penelitian yang digunakan pada penelitian ini adalah berupa studi kasus. Menurut (Rahayu, 2020) bahwa studi kasus adalah penelaahan secara empiris yang menyelidiki suatu gejala dalam latar kehidupan nyata. Hasil penelitian ini dikumpulkan dengan data primer dan data skunder, Penentuan teknik pengumpulan data yang tepat sangat menentukan kebenaran ilmiah suatu penelitian. Teknik pengumpulan data yang digunakan dalam penelitian ini adalah:

1. Observasi

Observasi adalah bagian dari proses penelitian secara langsung terhadap fenomena -fenomena yang hendak diteliti (Hanafiah, 2021). Dengan metode ini, peneliti dapat melihat dan merasakan secara langsung suasana dan kondisi subyek penelitian. Hal-hal yang diamati dalam penelitian ini adalah tentang Capaian Standar Pengelolaan Pendidikan Pada SD, SMP Dan SMA Islam Di Kota Bandung.

2. Wawancara

Teknik wawancara dalam penelitian ini adalah wawancara terstruktur, yaitu wawancara yang dilakukan dengan menggunakan pedoman yang telah ditetapkan sebelumnya, pertanyaan disusun secara ketat dan pertan- 
yaan sama pada setiap subjek (Sugiyono, 2015).

3. Dokumentasi

Dokumentasi adalah salah satu teknik pengumpulan data melalui dokumen atau catatan-catatan tertulis yang ada (Juhji, 2020). Dokumentasi berasal dari kata dokumen, yang berarti barang-barang tertulis. Di dalam melaksanakan metode dokumentasi, peneliti menyelidiki benda-benda tertulis, seperti bukubuku, majalah, notula rapat, dan catatan harian. Menurut Moleong dalam (Mayasari, 2021) bahwa metode dokumentasi adalah cara pengumpulan informasi atau data-data melalui pengujian arsip dan dokumendokumen. Strategi dokumentasi juga merupakan teknik pengumpulan data yang diajukan kepada subyek penelitian. Metode pengumpulan data dengan menggunakan metode dokumentasi ini dilakukan untuk mendapatkan data tentang keadaan lembaga (obyek penelitian) yaitu keberadaan pengelolaan pendidikan pada SD, SMP Dan SMA Islam di Kota Bandung, dan keadaan stafnya. Menurut Muhadjir dalam (Marantika, 2020) menyatakan bahwa analisis data merupakan kegiatan melakukan, mencari dan menyusun catatan temuan secara sistematis melalui pengamatan dan wawancara sehingga peneliti fokus terhadap penelitian yang dikajinya. Setelah itu, menjadikan sebuah bahan temuan untuk orang lain, mengedit, mengklasifikasi, dan menyajikannya.

Adapun pendekatan yang digunakan dalam penelitian ini adalah pendekatan kualitatif. Menurut Bogdan dan Taylor dalam (Bahri, 2021) menyatakan pendekatan kualitatif adalah prosedur penelitian yang menghasilkan data deskriptif berupa kata-kata tertulis atau lisan dari orangorang dan perilaku yang dapat diamati. Caranya dengan mentranskripsikan data, kemudian pengkodean pada catatan-catatan yang ada di lapangan dan diinterpretasikan data tersebut untuk memperoleh kesimpulan.

\section{HASIL DAN PEMBAHASAN}

Hasil penelitian ini terkait Capaian Standar Pengelolaan Pendidikan Pada SD, SMP Dan SMA Islam Di Kota Bandung. Data hasil penelitian terkait Capaian Standar Pengelolaan Pendidikan Pada SD, SMP Dan SMA Islam Di Kota Bandung berdasarkan hasil pengolahan data, maka pada bagian ini akan dibahas tentang bebarapa hal yaitu capaian standar pengelolaan tahun 20162020 pada sekolah sampel, perbandingan capaian standar pengelolaan di sekolah sampel di Kota Bandung, urutan nilai indikator mutu yang terendah sampai yang tertinggi, analisis akar masalah dan rekomendasi untuk perbaikan dan atau pengembangan standar pengelolaan di sekolah sampel

1. Capaian standar pengelolaan tahun 20162020 pada SD, SMP dan SMA Islam di Kota Bandung

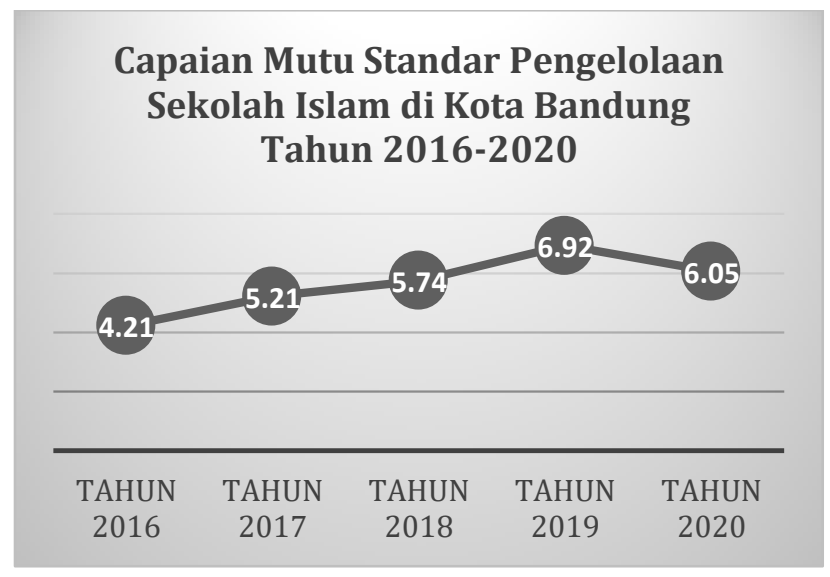

Gambar 1. Grafik Capaian Mutu Standar pengelolaan Sekolah Islam di Kota Bandung Tahun 2016-2020

Gambar diatas menunjukkan rerata nilai capaian standar pengelolaan sekolah Islam jenjang dasar dan menengah di Kota Bandung pada 4 tahun terakhir cenderung mengalami peningkatan terutama pada tahun 2019, ini merupakan salah satu implikasi dari implementasi kebijakan sistem penjaminan mutu pendidikan melalui penerapan SPMI di setiap pendidikan dasar dan menengah. Sedangkan pada tahun 2020 mengalami penurunan 0,87, salah satu factor penyebabnya adalah terjadinya pandemic covid 19 yang sangat signifikan berpengaruh pada kualitas pendidikan, termasuk pemenuhan standar pengelolaan pendidikan di satuan pendidikan dasar dan menengah.

1. Perbandingan capaian standar pengelolaan Sekolah Islam di Kota Bandung dengan rerata seluruh sekolah di Kota Bandung

Berdasarkan data yang tersedia, selanjutnya dilakukan perbandingan data capaian dari sekolah Islam yang ada di Kota Bandung dengan seluruh sekolah yang berada di wilayah Kota Bandung. Berikut adalah jumlah satuan pendidikan di Kota Bandung yang mengirimkan data mutu di tahun 2020. 
Tabel 1. Data Rapor Mutu SD, SMP, SMA Islam di Kota Bandung

\begin{tabular}{ccc}
\hline Jenjang & $\begin{array}{c}\text { Jumlah Sekolah } \\
\text { Islam }\end{array}$ & Jumlah Sekolah \\
\hline SMA & 8 & 108 \\
\hline SMP & 15 & 240 \\
\hline SD & 25 & 452 \\
\hline TOTAL & 48 & 600 \\
\hline
\end{tabular}

Dari data rapor mutu sekolah yang ada selanjutnya diolah menjadi nilai rerata dan disandingkan agar dapat diperoleh informasi ketercapaian mutu standar jika dibandingkan dengan sekolah-sekolah lain yang berada di wilayah Kota Bandung. Dari hasil pengolahan yang dibedakan berdasarkan jenjang maka data menunjukkan bahwa sekolah-sekolah Islam di Kota Bandung memiliki nilai capaian yang lebih tinggi jika dibandingkan dengan rerata nilai keseluruhan mutu standar pengelolaan di Kota Bandung, ini menunjukkan bahwa pengelolaan di sekolah Islam di Kota Bandung secara umum telah mengimplementasikan pengelolaan yang sesuai dengan tuntutan standar nasional pendidikan. Lebih jelas tergambar pada gambar berikut ini:

\section{PERBANDINGAN CAPAIAN MUTU STANDAR PENGELOLAAN SEKOLAH}

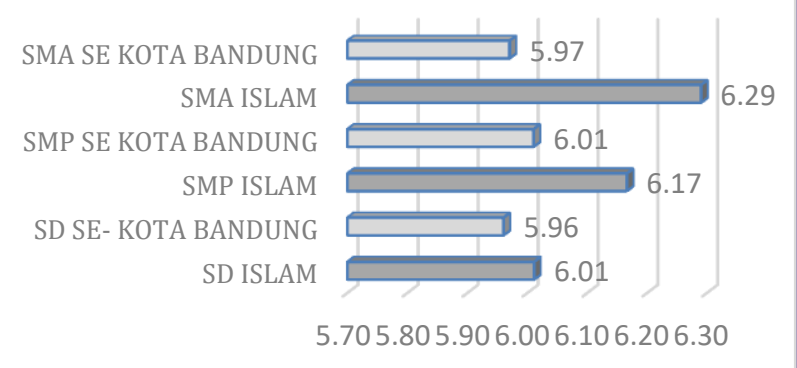

Gambar 2. Grafik Perbandingan rerata capaian mutu standar pengelolaan Sekolah

2. Pengelompokan data capaian mutu standar pengelolaan berdasarkan komponen dan jenjang

Langkah selanjutnya data yang tersedia dikelompokkan berdasarkan jenjang untuk melihat kebutuhan secara spesifik pada setiap komponen dan jenjang sekolah. Data hasil pengelompokkan menunjukkan bahwa dari empat komponen pada standar pengelolaan, secara umum pada setiap komponan untuk sekolah jenjang SD masih memiliki nilai capaian yang lebih rendah dibandingkan jenjang SMP dan SMA, terutama pada komponen pengelolaan sistem informasi manajemen.
Adapun untuk jenjang SMA unggul dalam capaian mutu komponen pengelolaan sistem informasi manajemen. Sedangkan pada komponen yang lainnya memiliki kecenderungan yang relative sama. Secara jelas terlihat pada grafik berikut:

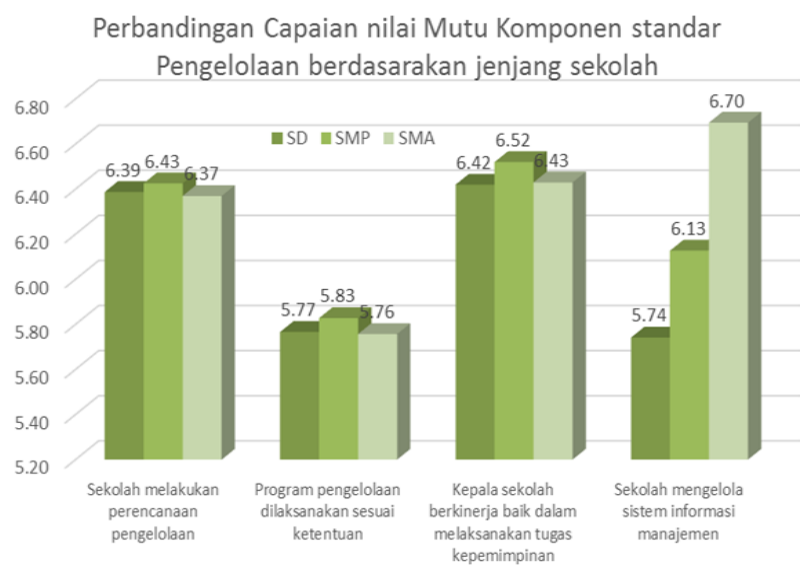

Gambar 3. Grafik Capaian standar pengelolaan perbandingan SD, SMP, SMA Islam di Kota Bandung

3. Capaian Mutu pada Komponen Standar Pengelolaan Pendidikan

Berikut adalah grafik yang menyajikan rerata nilai capaian setiap komponen dan indikator pada standar pengelolaan berdasarkan rapor mutu tahun 2020, yang terdiri dari 4 komponan yaitu (1) sekolah melakukan perencanaan pengelolaan, (2) program pengelolaan dilaksanakan sesuai ketentuan, (3) kepala sekolah berkinerja baik dalam melaksanakan tugas kepemimpinan dan (4) sekolah mengelola sistem informasi manajemen.

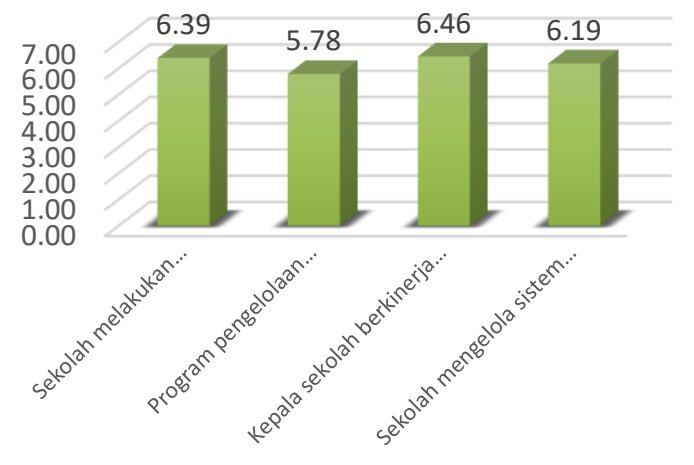

Gambar 4. Grafik Rerata Nilai Capaian Komponen standar pengelolaan pada sekolah Islam di Kota Bandung 
4. Urutan Nilai Capaian Indikator Standar Pengelolaan Berdasarkan Rapor Mutu Tahun 2020

Untuk melihat kebutuhan yang lebih spesifik, selanjutnya diurutkan capaian berdasarkan indikator dari mulai yang paling rendah capaiannya hingga yang paling tinggi. Perangkingan ini dilakukan supaya memudahkan satuan pendidikan dan stakeholder pendidikan dalam mengidentifikasi kebutuhan serta membuat prioritas program peningkatan mutu. Berikut adalah tabel urutan nilai indikator dari terendah ke tertinggi.

Tabel 2. Urutan capaian Indikator standar pengelolaan dengan Nilai terendah hingga tertinggi

\begin{tabular}{|c|c|c|c|}
\hline $\begin{array}{l}\text { NO } \\
\text { URUT }\end{array}$ & KODE & INDIKATOR & $\begin{array}{l}\text { RERATA } \\
\text { CAPAIAN }\end{array}$ \\
\hline 1 & 1.2 .2 & $\begin{array}{l}\text { Menyelenggarakan kegiatan } \\
\text { layanan kesiswaan }\end{array}$ & 5,16 \\
\hline 2 & 1.2 .6 & $\begin{array}{l}\text { Melaksanakan pengelolaan } \\
\text { bidang kurikulum dan kegiatan } \\
\text { pembelajaran }\end{array}$ & 5,19 \\
\hline 3 & 1.2 .4 & $\begin{array}{l}\text { Melaksanakan kegiatan evaluasi } \\
\text { diri }\end{array}$ & 5,70 \\
\hline 4 & 1.3 .5 & Berjiwa kewirausahaan & 5,86 \\
\hline 5 & 1.2 .3 & $\begin{array}{l}\text { Meningkatkan dayaguna pendidik } \\
\text { dan tenaga kependidikan }\end{array}$ & 5,98 \\
\hline 6 & 1.2 .5 & $\begin{array}{l}\text { Membangun kemitraan dan } \\
\text { melibatkan peran serta } \\
\text { masyarakat serta lembaga lain } \\
\text { yang relevan }\end{array}$ & 5,98 \\
\hline 7 & 1.4 .1 & $\begin{array}{l}\text { Memiliki sistem informasi } \\
\text { manajemen sesuai ketentuan }\end{array}$ & 6,17 \\
\hline 8 & 1.1 .2 & $\begin{array}{l}\text { Mengembangkan rencana kerja } \\
\text { sekolahdengan ruang lingkup } \\
\text { sesuai ketentuan }\end{array}$ & 6,20 \\
\hline 9 & 1.1 .3 & $\begin{array}{l}\text { Melibatkan pemangku } \\
\text { kepentingan sekolah dalam } \\
\text { perencanaan pengelolaan sekolah }\end{array}$ & 6,23 \\
\hline 10 & $\begin{array}{c}1.3 .2 \\
.\end{array}$ & Berjiwa kepemimpinan & 6,31 \\
\hline 11 & 1.2 .1 & $\begin{array}{l}\text { Memiliki pedoman pengelolaan } \\
\text { sekolah lengkap }\end{array}$ & 6,58 \\
\hline 12 & 1.3 .6 & Melakukan supervisi dengan baik & 6,59 \\
\hline 13 & 1.3 .3 & $\begin{array}{l}\text { Mengembangkan sekolah dengan } \\
\text { baik }\end{array}$ & 6,60 \\
\hline 14 & 1.1.1 & $\begin{array}{l}\text { Memiliki visi, misi, dan tujuan } \\
\text { yang jelas sesuai ketentuan }\end{array}$ & 6,65 \\
\hline 15 & 1.3 .1 & $\begin{array}{l}\text { Berkepribadian dan bersosialisasi } \\
\text { dengan baik }\end{array}$ & 6,68 \\
\hline 16 & 1.3 .4 & $\begin{array}{l}\text { Mengelola sumber daya dengan } \\
\text { baik }\end{array}$ & 6,68 \\
\hline
\end{tabular}

Dari tabel ini menunjukkan bahwa program prioritas dalam memenuhi standar pengelolaan adalah (1) penyelenggaraan kegiatan kesiswaan, (2) pengelolaan bidang kurikulum, (3) evaluasi diri sekolah, (4) kompetensi kewirausahaan Kepala Sekolah, (5) pendayagunaan PTK dan (6) membangun kemitraan dan pelibatan masyarakat sekitar.

\section{SIMPULAN DAN SARAN}

\section{A. Simpulan}

Berdasarkan hasil penelitian dan pembahasan yang telah disajikan maka dapat diambil simpulan bahwa hasil analisis yang dilakukan dapat disimpulkan bahwa, capaian standar pengelolaan di SD, SMP, dan SMA Islam di Kota Bandung termasuk pada kategori menuju SNP 4 dengan capaian skor 6,16 yang artinya capaian mutu pada standar pengelolaan di sekolah Islam baik jenjang SD, SMP dan SMA belum ada yang memenuhi standar nasional Pendidikan dengan rentang skor 6,67-7. Namun demikian progress kemajuan pemenuhan standar pengelolaan pada empat tahun terakhir mengalami peningkatan yang cukup signifikan yaitu sebesar 2,71, pada tahun 2016 masih termasuk kategori Menuju SNP 3, di tahun 2019 levelnya meningkat menjadi kategori SNP. Capaian standar pengelolaan yang belum memenuhi SNP tidak hanya pada sekolah Islam, namun hampir seluruh satuan Pendidikan di Kota Bandung pun secara umum belum memenuhi standar nasional pendidikan, setelah disandingkan antara capaian nilai rapor mutu pada sekolah islam dengan rerata capaian nilai rapor mutu seluruh satuan Pendidikan di Kota Bandung hasilnya menunjukkan bahwa capaian nilai rapor mutu standar pengelolaan sekolah islam lebih lebih tinggi daripada rerata capaian seluruh sekolah di kota Bandung berdasarkan rapor mutu tahun 2020.

\section{B. Saran}

Adapun saran yang dapat disampaikan berdasarkan hasil kesimpulan penelitian, dapat dikemukakan beberapa saran untuk ditindak lanjuti, baik bagi penelitian yang akan datang maupun pihak terkait. Kepala sekolah sebagai pelaku utama dalam menjalankan kegiatan pengelolaan sekolah, perlu melakukan tahapan-tahapan kegiatan pengelolaan mulai dari perencanaan, pelaksanaan, pemantauan dan evaluasi sesuai dengan standar yang telah ditetapkan pemerintah sebagai bagian dari sistem Pendidikan nasional dan diharapkan dengan memaksimalkan pemenmuhan standar pengelolaan maka layanan kepada peserta didik akan semakin meningkat yang berdampak pada kualitas lulusan yang terstandar dan sesuai kebutuhan. Penelitian ini juga diharapkan dapat dilanjutkan dengan penelitian lanjutan terkait implementasi standar pengelolaan, keterkaitan 
antara 8 SNP, model penjaminanan mutu dan pengembangan standar pengelolaan bagi sekolah dan madrasah dalam upaya meningkatkan mutu layanan pendidikan bagi peserta didik.

\section{DAFTAR RUJUKAN}

Afifudin. (2008). Pengelolaan Pendidikan "Teori Dan Praktek". Bandung: Prospect.

Arifudin, O. (2019). Manajemen Sistem Penjaminan Mutu Internal (SPMI) Sebagai Upaya Meningkatkan Mutu Perguruan Tinggi. MEA (Manajemen, Ekonomi, \& Akuntansi), 3(1), 161-169.

Arifudin, 0. (2020). Implementasi Sistem penjaminan mutu internal (SPMI) Sebagai Upaya Meningkatkan Mutu Program Studi. Jurnal Al-Amar (Ekonomi Syariah, Perbankan Syariah, Agama Islam, Manajemen Dan Pendidikan), 1(3), 1-11.

Arifudin, 0. (2021). Implementasi Balanced Scorecard dalam Mewujudkan Pendidikan Tinggi World Class. Edumaspul: Jurnal Pendidikan, 5(2), 767-775.

Asmedy, A. (2021). Perbandingan Hasil Belajar Matematika Siswa yang diajar dengan Model Pembelajaran Possing Problem Berkelompok dan Metode Ceramah. Jurnal Inovasi, Evaluasi Dan Pengembangan Pembelajaran (JIEPP), 1(2), 69-75. https://doi.org/10.54371/jiepp.v1i2.107

Bahri, A. S. (2021). Pengantar Penelitian Pendidikan (Sebuah Tinjauan Teori dan Praktis). Bandung: Widina Bhakti Persada.

Hanafiah, H. (2021). Pelatihan Software Mendeley Dalam Peningkatan Kualitas Artikel Ilmiah Bagi Mahasiswa. Jurnal Karya Abdi Masyarakat, 5(2), 213-220.

Hasbi, I. (2021). Administrasi Pendidikan (Tinjauan Teori Dan Praktik). Bandung: Widina Bhakti Persada.

Irwansyah, R. (2021). Perkembangan Peserta Didik. Bandung : Widina Bhakti Persada.
Jamaah, J. (2021). Peran Guru dalam Pembelajaran Home visit di Masa Pandemi Covid-19 pada Siswa Sekolah Dasar. Jurnal Inovasi, Evaluasi Dan Pengembangan Pembelajaran (JIEPP), 1(1), 1-10. https://doi.org/10.54371/jiepp.v1i1.74

Juhji. (2020). Manajemen Humas Sekolah. Bandung: Widina Bhakti Persada.

Marantika, N. (2020). Manajemen Humas Sekolah. Bandung: Widina Bhakti Persada Bandung.

Mayasari, A. (2021). Implementasi Sistem Informasi Manajemen Akademik Berbasis Teknologi Informasi dalam Meningkatkan Mutu Pelayanan Pembelajaran di SMK. JIIPJurnal Ilmiah Ilmu Pendidikan, 4(5), 340345. https://doi.org/10.54371/jiip.v4i5.277

Na'im, Z. (2021). Manajemen Pendidikan Islam. Bandung: Widina Bhakti Persada.

Nurhasanah, E. (2021). Peran Orang tua dalam Membimbing Anak Usia Sekolah Dasar di Rumah pada Masa Pandemi Covid19. Jurnal Inovasi, Evaluasi Dan Pengembangan Pembelajaran (JIEPP), 1(1), 11-18.

https://doi.org/10.54371/jiepp.v1i1.75

Raharjo. (2018). Capaian Standar Nasional Pendidikan Sebagai Prediktor Mutu Sekolah. Jurnal Pendidikan Dan Kebudayaan, 3(2), 55-69.

Rahayu, Y. N. (2020). Program Linier (Teori Dan Aplikasi). Bandung: Widina Bhakti Persada.

Rinjani, C., Wahdini, F. I., Mulia, E., Zakir, S., \& Amelia, S. (2021). Kajian Konseptual Model Pembelajaran Word Square untuk Meningkatkan Hasil Belajar Siswa. Jurnal Inovasi, Evaluasi Dan Pengembangan Pembelajaran (JIEPP), 1(2), 52-59. https://doi.org/10.54371/jiepp.v1i2.102

Sugiyono. (2015). Metode Penelitian Pendidikan (Pendekatan Kuantitatif.. Kualitatif dan $R \& D$ ). Bandung : CV. Alfabeta. 